Current Research Journal of Social Sciences 11(1): 1-12, 2020

DOI:10.19026/crjss.11.6050

ISSN: 2041-3238, e-ISSN: 2041-3246

(C) 2020 Maxwell Scientific Publication Corp.

\begin{tabular}{lll}
\hline Submitted: March 9, 2020 & Accepted: April 27, 2020 & Published: August 25, 2020
\end{tabular}

\title{
Research Article \\ Food Consumption Patterns and Predictors of Dietary Diversity in Pastoral Communities of Ngorongoro District, Tanzania
}

\author{
John G. Safari, Shauri K. Timothy and Zacharia S. Masanyiwa \\ Institute of Rural Development Planning, P.O. Box 138, Dodoma, Tanzania
}

\begin{abstract}
The aim of this study was to assess the patterns of household food consumption and examine the factors influencing dietary diversity. Data were collected from 238 randomly selected households. Food consumption was assessed in terms of Dietary Diversity Score (DDS) with a range of 0-12. The minimum and maximum DDS were one and eight, respectively. Groups of food consumed were classified into four Quantiles (Q) and households were categorized based on quartile cut-points: Q1 (1-3 DDS), Q2 (4), Q3 (5-6) and Q4 (7-8). Chi square test was used to assess the association between the food groups and quartile level. Ordered probit regression was employed to examine determinants for household dietary diversity. Results show that more than four in ten households (43.3\%) consumed less than the minimum recommended four groups of food. Proportions of households consistently decreased with increasing quartile level (43.3\% in Q1 to 6.7\% in Q4). Only 18\% of the households were in the upper quartiles (Q3 and Q4). The DDS means by quartiles were 2.47 (Q1), $4.00(\mathrm{Q} 2), 5.00(\mathrm{Q} 3)$ and $5.89(\mathrm{Q} 4)$ with the overall mean DDS of 3.52 . While cereal $(96.2 \%$ of the households) was the most consumed food group, there was limited consumption of vegetables (12.6\%), fruits (4.2\%) and fish (2.9\%). Food accessibility and livelihood diversification were the major determinants of dietary diversity. Demographic and socio-economic factors mediated household's dietary diversity at varying degree of influence.
\end{abstract}

Keywords: Dietary diversity, dietary quality, food security, Maasai, ordered probit, pastoralism

\section{INTRODUCTION}

Food insecurity and micronutrient malnutrition are widespread public health problems that can be alleviated in part through increasing dietary diversity (Harris-Fry et al., 2015; Mphwanthe et al., 2018; Larson et al., 2019). Dietary Diversity Score (DDS), a qualitative measure of food consumption, has become a widely used method of determining variety in the diet and by proxy, nutrient adequacy (Labadarios et al., 2011; Arsenault et al., 2013; Martin-Prével et al., 2015). It measures the consumption of different food groups by any member of a given household over a reference period and used as an indicator of food security (Galiè et al., 2019).

Studies show that higher DDS is positively associated with an increased nutrient intake, better nutritional status, dietary quality, food security and the overall wellbeing (Vandevijvere et al., 2010; Nti, 2011; Lo et al., 2012; Hooshmand and Udipi, 2013; Ares et al., 2014; Mekuria et al., 2017). Conversely, an emerging body of literature shows that low diversity in diets is associated with increased risk of chronic undernutrition and micro-nutrient deficiencies with particular concerns in young children and elderly people (Rah et al., 2010). Negative health consequences of low dietary diversity include cognitive impairment (Lv et al., 2019), child stunting (Mahmudiono et al., 2017), cardiovascular risk (Farhangi and Jahangiry, 2018), dyslipidemia (Li et al., 2011), higher probability of metabolic syndrome (Gholizadeh et al., 2018) and higher risk of mortality (Lv et al., 2019; Gebremedhin et al., 2017).

Indeed, DDS has been identified as a key indicator for surveillance of actions that aim to tackle various nutrition-related problems and food insecurity (Workicho et al., 2016). It provides information on the contribution of different food groups to the diet which sheds light on its quality and nutrient adequacy in a population. DDS varies across population groups, cultures and socio-economic levels (Keding et al., 2012; Powell et al., 2015; Kasimba et al., 2018). Further, it has been documented that there can be positive, neutral or even negative associations between agricultural production and dietary diversity (Sibhatu et al., 2015; Ickowitz et al., 2019). The varying nature

Corresponding Author: John G. Safari, Institute of Rural Development Planning, P.O. Box 138, Dodoma, Tanzania This work is licensed under a Creative Commons Attribution 4.0 International License (URL: http://creativecommons.org/licenses/by/4.0/). 
Curr. Res. J. Soc. Sci., 11(1): 1-12, 2020

between the production system and diets, points to the need for contextualizing site-specific linkages between the mode of livelihood and dietary diversity (Ritzema et al., 2019).

Pastoralism, a focus of this study, is itself an agricultural production system characterized by mobility of animals, with more than $50 \%$ of household gross revenue from livestock or livestock related activities (FAO, 2001). While literature finds a generally more food secure situation in most parts of Tanzania, there are reports indicating high level of persistent food insecurity among pastoralists (Yanda and William, 2010; Knueppel et al., 2010; Coulibaly et al., 2015). There are also records that pastoral areas are more prone to malnutrition (Loos and Zeller, 2014; Galvin et al., 2015). Climate variability, cattle diseases and unpredictable markets have been reported as important causes of food insecurity in these communities (Misiak et al., 2018). It is further noted that poverty and malnutrition, stemming from historical determinants of land access and land tenure, are compounded by deterioration of pastures and other aspects of the biophysical environment associated with integration of pastoralists into the market economy (Oiye et al., 2009; Lynn, 2010; Rufino et al., 2013). At the face of the nutritional related challenges in pastoral areas, information on food consumption patterns and dietary diversity is rather limited. Evaluating food consumption patterns and associated factors will inform the various nutritional initiatives in the country. Thus, the aim of this study was to assess the patterns of household food consumption and examine the factors influencing dietary diversity in pastoral communities.

\section{METHODOLOGY}

Study area: The data presented in this study were derived from an empirical cross sectional study which was conducted in July, 2019 in pastoral communities of Ngorongoro District in Northern Tanzania. Data were collected from the inhabitants of Maasai villages (bomas) located around Nainokanoka Ward in the Ngorongoro Conservation Area (NCA). Specifically, the study was conducted in three purposively selected villages; Nainokanoka, Erkeepusi and Bulati. The Maasai people form the dominant tribe in these villages whose main livelihood activity is transhumance livestock keeping of cattle, goats and sheep. To preserve wildlife, the Maasai of Ngorongoro are prohibited to cultivate in the NCA. Traditionally, the Maasai are semi-nomadic pastoralists who migrate within semi-arid lowlands and more humid uplands to obtain water and pasture for their livestock. This semiarid area experiences seasonal rainfall, with wet seasons falling between April and May and between November and December. The average annual rainfall ranges from
500 to $1700 \mathrm{~mm}$. The area faces limited water supply with acute shortages for several months a year.

Data collection: Sample size $(n)$ estimation was performed using a formula $z^{2} \times p(1-p) / d^{2}$ (Cochran, 1977); where; $z^{2}=$ critical value $(1.96$ for $95 \%$ confidence level); $p=$ percentage of households consuming the minimum diverse diet $(0.5$ was used in order to maximize sample size); $d=$ maximum error and a design effect of 2. A total of 194 households had to be included for a statistical representative sample. An additional 44 households were selected to provide for possible dropout or non-response incidences. Thus, the final sample consisted of 238 randomly selected households. Informed verbal consent was obtained from the study participants before proceeding with interviews. The study involved use of questionnaires which were initially prepared in English. However, interviews were conducted in native language Maa and later translated back to English. Household DDS was assessed as described in Kant et al. (1993) which involves asking respondents to recall all the dishes they had consumed the previous $24 \mathrm{~h}$. DDS is a common indicator that counts the number of food groups consumed at least once in a period of $24 \mathrm{~h}$ (Steyn et al., 2014). Food items were classified into 12 different food groups as proposed by the Food and Agriculture Organization of the United Nations (FAO, 2011). These were cereals, tubers, legumes, meat, eggs, vegetables, fruits, oil, sweets, milk, fish and sugar or honey. Each food group counted toward the household score adding "1" if any family member consumed a food item from the group. Dietary diversity score was constructed by adding up the number of food groups represented in the diet of the previous $24 \mathrm{~h}$. Possible minimum and maximum household dietary diversity scores were 0 and 12 , respectively.

Potential factors influencing household dietary diversity were inquired. The factors included age of the household head, sex of the household head, education level of the household head, household size, age distribution of the household members, the household main economic activity, type and number of livestock and distance to the nearest road and to the market. Others were those related to food availability, food access and average number of meals per day in the previous 30 days. Food availability was measured in terms of Months of Adequate Food Provisioning (MAHFP) score with a range of 0-12. MAHFP is defined as the number of months per year that households report no food shortages (Bilinsky and Swindale, 2010). Presence or lack of food storage facility was used as a proxy indicator of food availability. Household Food Insecurity Access Scale (HFIAS) score with a range of 0-27 was measured based on the frequency of occurrence of food insecurity related conditions as described in food security 
indicator guideline (Coates et al., 2007). Households were then categorized as food secure if HFIAS $<17$ or food insecure if HFIAS $\geq 17$ (FAO, 2008).

Theoretical framework: The fundamental objective of this study was to analyze food consumption and examine the predictors of dietary diversity. In this regard, food consumption was assumed to be an outcome of a given set of food attributes and individual preferences (Otieno and Nyikal, 2017). Thus, food consumption patterns can be modelled as a consumer utility problem which is hypothesized to be a function of various factors including socio-economic characteristics as well as nutritional attributes of food (Rimal et al., 2000; Pritchard et al., 2019; Muricho et al., 2019). Following the work of Lancaster (1966), the amount of the nutritional attribute an individual derives is the sum of each attribute of food group consumed by the household during a given reference period. This amount can be represented as $F_{P}=\sum_{i} \delta_{P i} X_{i}$, whereby $F_{p}$ is the amount of $p^{\text {th }}$ nutritional attribute of F, $\delta_{P i}$ is the unit of $F_{P}$ in food $i$ and $X_{i}$ is quantity of food $i$ consumed. However, as highlighted earlier, the consumption of a particular food is also influenced by socio-economic characteristics. Thus, an individual's consumption pattern is directly reflected in the maximized utility function denoted as:

$$
U_{j}^{*}=\beta^{\prime} X_{j}+\mu_{i}
$$

$$
\begin{array}{ll}
\text { where, } & \\
U_{j}^{*}: & \begin{array}{l}
\text { The utility level attained by the } \mathrm{j}^{\text {th }} \\
\text { household }
\end{array} \\
X_{j}: \begin{array}{l}
\text { A vector of explanatory variables including } \\
\text { household demographics, socio-economic } \\
\text { characteristics and food related attributes }
\end{array} \\
\quad: \begin{array}{l}
\text { The independently, identically and } \\
\text { normally distributed error term }
\end{array}
\end{array}
$$

From (1), the utility level attained by the $j^{\text {th }}$ household $\left(U_{j}^{*}\right)$ is not observed (latent variable). What is observed is the indicated dietary diversity score that reflects nutritional attributes attained by consuming specific food groups. Basically, choice models such as logit or probit are suitable for estimating the utility functions (Smale et al., 2015; Gomez et al., 2015; Hirvonen et al., 2017). Because the variable dietary diversity has a natural ordering, an ordered probit model was considered in estimating the utility function on the ground that this model would give better and unbiased results (Fetai et al., 2015; Ziegler, 2019; Muraoka et al., 2018; Muricho et al., 2019). An ordered probit is a generalization of the probit analysis of the case of more than two outcomes of an ordinal dependent variable. In the analysis, the dietary diversity scores were categorized in Quantiles $(Q)$ such that: $Q_{1}=1-3$ food groups; $Q_{2}=4 ; Q_{3}=5-6$ and $Q_{4}=7-8$ with $\alpha_{i}$ threshold. These categories can be represented in Eq. (2)-(5) as follows:

$$
\begin{aligned}
& Q=1, \text { if } U_{j}^{*} \leq \alpha_{1} \\
& Q=2, \text { if } \alpha_{1}<U_{j}^{*} \leq \alpha_{2} \\
& Q=3, \text { if } \alpha_{2}<U_{j}^{*} \leq \alpha_{3} \\
& Q=4, \text { if } \alpha_{3}<U_{j}^{*}
\end{aligned}
$$

Data analysis: Data were encoded and analysed using Stata statistical software (version 13). The respondents were categorized according to the cut-points of DDS in quartiles Q1, Q2, Q3 and Q4. Household distribution of consumption of food groups and DDS quartiles were analysed using Pearson's Chi-square test. To test for collinearity between variables, data were subjected to analysis of Variance Inflation Factors (VIFs). The VIF indicates whether a predictor has a strong linear relationship with the other predictor(s). Analysis showed low values of VIFs ranging between 1.02 and 2.13. Variables were, therefore, statistically valid for inclusion in the model as they were all $<10$ (Myers, 1990; Field, 2013).

The dependent factors were ordinal variables ranked as Q1, Q2, Q3 and Q4. Independent variables included a set of categorical variables. A binary variable was denoted " 1 " if age of the household head is above 35 , sex of the household head is male, household head attended school, household diversified livelihood activities (petty business and beekeeping), owned food storage facility, had membership to a saving group and was categorized as food insecure. Others were continuous variables which included household size, dependency ratio, Total Livestock Unit (TLU), MAHFP, distance to the nearest road and to the market. Dependency ratio was defined as the number of dependent children $<18$ years of age plus the number of dependent elderly over 65 years of age relative to the number of working aged adults in the household (Coates et al., 2018). Variables that showed wide variation among households were log transformed. Marginal effects were calculated as a discrete change from $0-1$ for dummy variables and at means for continuous variables.

\section{RESULTS}

Characteristics of the study participants: Results in Table 1 show that majority of respondents $(61.3 \%)$ were above 35 years of age, male $(82.3 \%)$ and had not attended formal education (61.7\%). The average household size was 6.6. The main economic activities were pastoralism only (52.5\% of the households), 
Curr. Res. J. Soc. Sci., 11(1): 1-12, 2020

Table 1: Summary statistics

\begin{tabular}{|c|c|c|c|c|c|c|}
\hline \multirow{2}{*}{$\begin{array}{l}\text { Variable } \\
\text { Household demographics }\end{array}$} & \multirow[t]{2}{*}{$\mathrm{N}$} & \multirow[t]{2}{*}{$(\%)$} & \multirow[t]{2}{*}{ Mean DDS } & \multirow[t]{2}{*}{ S.E. } & \multicolumn{2}{|c|}{$95 \%$ C.I } \\
\hline & & & & & & \\
\hline \multicolumn{7}{|l|}{ Age (years) } \\
\hline$\leq 35$ & 92 & 38.7 & 3.41 & 0.11 & 3.18 & 3.63 \\
\hline$>35$ & 146 & 61.3 & 3.58 & 0.09 & 3.39 & 3.76 \\
\hline \multicolumn{7}{|l|}{ Sex of household head } \\
\hline Male & 196 & 82.3 & 3.52 & 0.08 & 3.36 & 3.67 \\
\hline Female & 42 & 17.7 & 3.50 & 0.17 & 3.15 & 3.87 \\
\hline \multicolumn{7}{|l|}{ Attended school } \\
\hline Yes & 91 & 38.3 & 3.75 & 0.11 & 3.52 & 3.97 \\
\hline No & 147 & 61.7 & 3.37 & 0.09 & 3.19 & 3.55 \\
\hline Household size, mean $=6.6$ & 235 & 100 & 3.54 & 0.77 & 3.39 & 3.70 \\
\hline Household dependency ratio, mean $=0.3$ & 236 & 100 & 3.53 & 0.07 & 3.39 & 3.66 \\
\hline \multicolumn{7}{|l|}{ Household economic activities } \\
\hline Pastoralism only & 125 & 52.5 & 3.24 & 0.09 & 3.04 & 3.43 \\
\hline Pastoralism and petty business & 80 & 33.6 & 3.78 & 0.12 & 3.53 & 4.02 \\
\hline Pastoralism and beekeeping & 33 & 13.9 & 3.94 & 0.15 & 3.63 & 4.24 \\
\hline Livestock holding, mean TLU $=44$ & 238 & 100 & 3.52 & 0.07 & 3.37 & 3.66 \\
\hline \multicolumn{7}{|l|}{ Household location } \\
\hline Distance to road, mean $=11.4 \mathrm{~km}$ & 238 & 100 & 3.52 & 0.07 & 3.37 & 3.66 \\
\hline Distance to market, mean $=12.5 \mathrm{~km}$ & 234 & 100 & 3.50 & 0.07 & 3.35 & 3.64 \\
\hline \multicolumn{7}{|l|}{ Household food related characteristics } \\
\hline MAHFP, mean $=6.8$ months & 238 & 100 & 3.52 & 0.07 & 3.37 & 3.66 \\
\hline \multicolumn{7}{|l|}{ Food storage facility } \\
\hline Present & 155 & 65.1 & 3.77 & 0.08 & 3.60 & 3.93 \\
\hline Absent & 83 & 34.9 & 3.04 & 0.12 & 2.81 & 3.26 \\
\hline \multicolumn{7}{|l|}{ HFIAS } \\
\hline Secure & 105 & 44.2 & 3.98 & 0.10 & 3.77 & 4.18 \\
\hline Insecure & 133 & 55.8 & 3.14 & 0.09 & 2.96 & 3.31 \\
\hline \multicolumn{7}{|l|}{ Meals/day } \\
\hline Two times & 113 & 48.3 & 3.28 & 0.09 & 3.08 & 3.47 \\
\hline Three times & 121 & 51.7 & 3.76 & 0.09 & 3.57 & 3.94 \\
\hline \multicolumn{7}{|l|}{ Quartile (Q) of DDS } \\
\hline Q1 & 103 & 43.3 & 2.47 & 0.06 & 2.33 & 2.60 \\
\hline Q2 & 92 & 38.7 & 4.00 & 0.05 & 3.89 & 4.10 \\
\hline Q3 & 27 & 11.3 & 5.00 & 0.09 & 4.79 & 5.20 \\
\hline Q4 & 16 & 6.7 & 5.89 & 0.15 & 5.57 & 6.20 \\
\hline All & 238 & 100 & 3.52 & 0.07 & 3.37 & 3.66 \\
\hline
\end{tabular}

DDS: Dietary diversity score; S.E.: Standard error; C.I.: Confidence interval; TLU: Tropical livestock unit computed on conversion factors of 0.7 and 0.1 for cattle and sheep/goat, respectively (FAO, 1979); HFIAS: Household food insecurity access scale; MAHFP: Months of adequate household food provisioning; Quantiles: 1, 2, 3, 4 represent dietary diversity scores 1-3, 4, 5-6 and 7-8, respectively

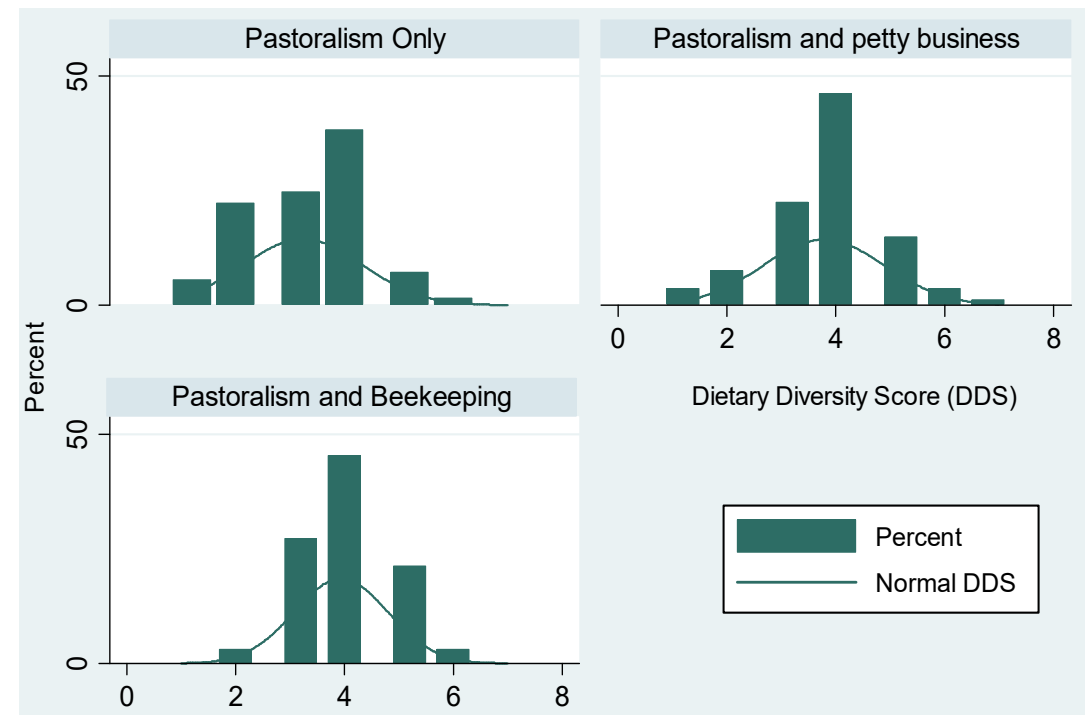

Fig. 1: Distribution of dietary diversity scores by household main economic activities 
Curr. Res. J. Soc. Sci., 11(1): 1-12, 2020

pastoralism and petty business (33.6\%) and pastoralism and beekeeping (13.9\%). Households exclusively dependent on pastoralism had the least score of dietary diversity. Engaging in petty business or beekeeping resulted in increased mean dietary diversity as depicted in Fig. 1. Households in the study areas are sparsely located with the average of 11.4 and $12.5 \mathrm{~km}$ to the road and to the nearest market, respectively. The average Months of Adequate Food Provisioning was 6.8. The HFIAS results showed that over half of the households (55.8\%) were food insecure with $48.3 \%$ having on average 2 meals/day. Greater proportion of households $(43.3 \%)$ were in the first quartile of the DDS consuming $<4$ groups of food. The proportions of households consistently decreased from Q1 to Q4. Only $18 \%$ of the households were in the upper quartiles (Q3 and Q4). The minimum and maximum DDS were one and eight, respectively. The DDS means by quartiles were $2.47(\mathrm{Q} 1), 4.00(\mathrm{Q} 2), 5.00(\mathrm{Q} 3)$ and $5.89(\mathrm{Q} 4)$ with the overall mean DDS of 3.52 .

Patterns of food consumption: Distributions of food group consumption across the quartile categories of dietary diversity are presented in Table 2 . The results show notable variations in the consumption of the food groups across the quartile levels. The most frequently consumed food groups were cereals $(96.2 \%$ of the households); coffee and tea (69.3\%); oil, fat and butter $(56.3 \%)$ and milk or milk products $(50.4 \%)$. Milk was often consumed after providing additives or adjuncts (herbs) to give it a special aroma. The most common herbs (in Maa language) are Oloirien, Orkonyiel, Ormisigiyey and Engaitarakway. The findings also showed low consumption rates of vegetables (12.6\%), fruits $(4.2 \%)$, fish $(2.9 \%)$ and eggs $(2.5 \%)$. Except for cereals and sugar and honey for which the consumption levels were similar across the quartile categories, the rest of the food groups varied significantly in consumption $(\mathrm{p}<0.05)$. In $\mathrm{Q} 1$, for example, some of the food groups were consumed in very small proportions (e.g., eggs, fish and vegetables, all $<2 \%$ of households) or not consumed at all (fruits, $0 \%$ ). Only cereals and milk and milk products were consumed in greater proportions in Q1. This could mean that households in Q1 mainly ate cereals as the main dish with milk and milk products as side dishes. Similarly, households in Q2 had low consumption levels of fruits $(2 \%)$, eggs (2\%) and fish (5\%). A relative higher consumption of fruits was observed in Q3 (19.2\%) and Q4 (33.3\%). As well, increased vegetable consumption can be noted from Q2 through Q4. Food groups consumed in greater proportions ( $>50 \%$ of households) were cereals (Q1 to Q4), milk and milk products (Q1 to Q4), coffee and tea (Q2-Q4), oil, fat and butter (Q2-Q4) and meat (Q4 only). Overall, with the exception of milk and milk products, there was very minimal consumption of animal source foods.

Predictors of household dietary diversity scores: Predictors of household DDS (Q1-Q4) were identified using marginal effects of the ordered probit regression analysis and results are presented in Table 3. The results infer to change in probability in a given quartile if a test variable or a household switches its status from " 0 " to " 1 " for categorical data and at means for continuous variables. Note that for each variable, the sum of probabilities across the quartiles equals zero. The HFIAS had the most significant effect on DDS. A household categorized as food insecure based on HFIAS indicator has $30 \%$ probability of falling into Q1. Its probability of being in Q2, Q3 and Q4 falls by 18, 11 and $2 \%$, respectively. The second most important factor influencing DDS was livelihood diversification. Households engaged in pastoralism and beekeeping or pastoralism and petty business reported more diverse diets compared with those involved in pastoralism only. Membership in saving group favoured higher dietary diversity. A household that belonged to a saving group had 14\% lower probability of being in Q1 and only 1\% in Q4. If a household changes from having few members $(\leq 6)$ to larger size $(>6)$, the predicted probability of a given household being in Q1 falls significantly by $6 \%$. Its chances of being categorized into Q2, Q3 and Q4 increases by 4,3 and $2 \%$,

Table 2: Percent distribution of households in food consumption by household dietary diversity score

\begin{tabular}{|c|c|c|c|c|c|c|c|}
\hline \multirow[b]{2}{*}{ Food group consumed } & \multirow[b]{2}{*}{ No } & \multirow[b]{2}{*}{ Yes } & \multicolumn{5}{|c|}{ Quartiles (Q) of dietary diversity scores (yes) } \\
\hline & & & Q1 & Q2 & Q3 & Q4 & p-value \\
\hline Roots and tubers & 90.3 & 9.7 & 1.9 & 16.0 & 19.2 & 0.0 & 0.002 \\
\hline Fruits & 95.8 & 4.2 & 0.0 & 2.0 & 19.2 & 33.3 & 0.000 \\
\hline Sugar and honey & 92.4 & 7.6 & 5.8 & 6.0 & 15.4 & 22.2 & 0.120 \\
\hline Cereals & 3.8 & 96.2 & 99.0 & 93.0 & 96.2 & 100 & 0.142 \\
\hline Eggs & 97.5 & 2.5 & 1.0 & 2.0 & 0.0 & 33.3 & 0.000 \\
\hline Fresh or dried fish & 97.1 & 2.9 & 1.0 & 5.0 & 3.8 & 0.0 & 0.000 \\
\hline Milk and milk products & 49.6 & 50.4 & 93.7 & 50.0 & 73.1 & 66.7 & 0.043 \\
\hline Coffee or tea & 30.7 & 69.3 & 49.5 & 82.0 & 88.5 & 100 & 0.000 \\
\hline Vegetables & 87.4 & 12.6 & 1.9 & 20.0 & 23.1 & 22.2 & 0.000 \\
\hline Oil, fat and butter & 43.7 & 56.3 & 24.3 & 76.0 & 92.3 & 100 & 0.000 \\
\hline Meat & 80.7 & 19.3 & 10.7 & 24.0 & 23.1 & 55.6 & 0.003 \\
\hline Beans & 79.8 & 20.2 & 7.8 & 24.0 & 46.2 & 44.4 & 0.000 \\
\hline
\end{tabular}


Curr. Res. J. Soc. Sci., 11(1): 1-12, 2020

Table 3: Marginal effects of demographic, socio-economic and food supply related factors in household dietary diversity

\begin{tabular}{|c|c|c|c|c|}
\hline \multirow[b]{2}{*}{ Variable } & \multicolumn{4}{|c|}{ Quartiles (Q) of dietary diversity scores } \\
\hline & Prob. $(\mathrm{Q}=1)$ & Prob. $(\mathrm{Q}=2)$ & Prob. $(\mathrm{Q}=3)$ & Prob. $(\mathrm{Q}=4)$ \\
\hline HH head age above 35 years, $(1 / 0)^{\mathrm{a}}$ & -0.04 & 0.02 & 0.02 & 0.01 \\
\hline Male HH head, $(1 / 0)^{\mathrm{a}}$ & 0.07 & -0.04 & -0.03 & -0.02 \\
\hline HH size $(\ln )$ & $-0.06^{* *}$ & $0.04^{* *}$ & $0.02^{* *}$ & 0.01 \\
\hline HH dependency ratio $(\ln )$ & $0.10^{* * *}$ & $-0.06^{* * *}$ & $-0.04^{* * *}$ & $-0.05^{*}$ \\
\hline HH head attended school, $(1 / 0)^{\mathrm{a}}$ & -0.04 & 0.02 & 0.01 & 0.01 \\
\hline Livestock holding, TLU (ln) & $-0.16^{* *}$ & $0.10^{* *}$ & $0.06^{* *}$ & 0.01 \\
\hline Livelihood diversification, $(1 / 0)^{\mathrm{a}}$ & $-0.18^{* * *}$ & $0.10^{* * *}$ & $0.06^{* * *}$ & $0.01^{*}$ \\
\hline HH owns storage facility, $(1 / 0)^{\mathrm{a}}$ & $-0.17^{* *}$ & $0.10^{* *}$ & $0.06^{* *}$ & 0.01 \\
\hline MAHFP $(\ln )$ & -0.01 & 0.01 & 0.01 & 0.00 \\
\hline HFIAS (HH is food insecure), $(1 / 0)^{\mathrm{a}}$ & $0.30^{* * *}$ & $-0.18^{* * *}$ & $-0.11^{* * *}$ & $-0.02^{* *}$ \\
\hline $\mathrm{HH}$ distance to nearest market $(\mathrm{km})(\mathrm{ln})$ & $0.03^{* *}$ & $-0.02^{*}$ & $-0.01^{*}$ & $-0.00^{*}$ \\
\hline HH distance to nearest road $(\mathrm{km})(\mathrm{ln})$ & $0.01^{* * *}$ & $-0.01^{* *}$ & $-0.01^{* * *}$ & $-0.01^{*}$ \\
\hline $\mathrm{HH}$ is member of a saving group $(1 / 0)^{\mathrm{a}}$ & $-0.14^{* * *}$ & $0.08^{* *}$ & $0.05^{* * * *}$ & 0.01 \\
\hline
\end{tabular}

Quantiles: 1, 2, 3, 4 represent dietary diversity scores 1-3, 4, 5-6 and 7-8, respectively; HH: Household; TLU: Tropical livestock unit; HFIAS: Household food insecurity access scale; MAHFP: Months of adequate household food provisioning; ${ }^{*}: \mathrm{p}<0.1 ;{ }^{* *}: \mathrm{p}<0.05 ;{ }^{* * *}: \mathrm{p}<0.01 ;{ }^{a}:$ Binary $(1 / 0)$

respectively. For continuous variables, their effects on dietary diversity are interpreted in a similar way. Taking the variable "TLU", for example, an increase of one TLU reduced the probability of a household being in Q1 category by $16 \%$ while its probability for Q2 and Q3 categories increases by 10 and 6\%, respectively. Similarly, an increase in one $\mathrm{km}$ from a household to the main road meant that the household had a $1 \%$ greater probability of belonging to Q1 and less probability to Q2-Q4 by $1 \%$ for each quartile. Of the thirteen explanatory variables included in the model, nine had significant influence on the dietary diversity (Table 3). Overall, lower HFIAS score, livelihood diversification, presence of food storage facility and higher TLU favoured diverse diets in that order. Other favourable factors were membership in saving group, lower dependency ratio, large family size and short distance to the nearest road and to the market.

\section{DISCUSSION}

Results from the present study have demonstrated that most households consumed less diversified diets. As documented previously, the diets offered in foodscarce environments are known for being monotonous and bulky and this has been described as the hallmark of poverty and poor nutrition (Moramarco et al., 2017). The mean DDS observed in this study compares well with the findings of other studies. These include a DDS of 3.1 in Zambia (Rosenberg et al., 2018), 3.1 in Malawi (Kang et al., 2019), 3.4 in Ethiopia (Weldehaweria et al., 2016) and 3.9 in Kenya (Bostedt et al., 2016). Several studies have identified sensitivity of nutrient adequacy with 4 food groups (Steyn et al., 2014; Dangura and Gebremedhin, 2017; Perkins et al., 2018). Thus, consumption of food from $<4$ groups represents the consumption of less than the minimum diverse diet and suggests that households had suboptimal levels of nutrient adequacy. Of note is that consumption of a diverse diet within and between food groups is considered as an indicator of healthy patterns (Tavakoli et al., 2016). A study conducted in Ethiopia, for example, found that children who take $<4$ food groups/day have higher probability of stunting than their counterparts (Demilew and Alem, 2019). In this perspective, it has been argued that the most sustainable way to address malnutrition is through promoting the consumption of a diet that is both high in quality and diverse (Rah et al., 2010). As noted in previous studies (Warren et al., 2015; Dafursa and Gebremedhin, 2019) and demonstrated in the current work, consumption levels of protein-rich foods is generally low which raises concerns for attaining desired health outcomes. The low consumption of protein-rich foods other than milk could possibly be due to several reasons. First, it could be due to limited supply of food varieties in the local market especially because of the perishable nature of some of these foods. Second, the low consumption of protein-rich foods could be associated with limited nutritional awareness and access due to economic constraints given that these foods are relatively more expensive. Third, the low consumption levels can be linked to food culture. Traditionally, the Maasai do not consider certain foods including fish and eggs as decent meals. Fish demand in the study area is very low and so is its supply in the local markets. Eggs collected in households raising chicken are normally meant for sale rather than for own consumption.

Although milk was the most common source of animal protein, its availability is limited during the lean season (July-December) as large number of animals migrate to areas with green pastures. Thus, there is a direct and positive relationship between availability of feed resources and household food availability. Reduction in consumption of milk adversely affects nutrition and food security during this season (Fenton et al., 2012). Results showed high consumption of oil, fat and butter. This could mainly be linked to a culture of preserving clarified butter or ghee (Engornonashola) for use especially during the dry season (Olamey) when 
Curr. Res. J. Soc. Sci., 11(1): 1-12, 2020

milk yield is low. At any one season, therefore, availability of oil, fat and butter is to a large extent guaranteed.

The findings have also showed that fruits and vegetables which are rich in micro-nutrients (WHO, 2002; Guenther et al., 2007), contributed to a significant share of under-consumed food groups. In a study that details Maasai food symbolism, it was described that the Maasai dietary ideal excludes and strongly devaluates all plant food (Århem, 1989). However, fruits and vegetables are specific food groups with high dietary antioxidants and multiple antiinflammatory components (Narmaki et al., 2015). They contain different types of vitamins, minerals, carotenoids, polyphenols and many other bioactive compounds (Brighenti et al., 2005). Thus, limited intake of these food groups results in negative health consequences. Misiak et al. (2018), for example, reported that Maasai children are frequently undernourished and reproductive-age women suffer from anemia because of the general scarcity of food and a lack of fruits and vegetables in their diets. Martin et al. (2014) reported that $29 \%$ of reproductive-age women of the NCA suffered from anemia. These observations suggest that a strong association exists between diets deficient in micronutrients and poor health status as reported elsewhere (Biesalski, 2013; Cano-Ibáñez et al., 2019). The observation on the predominance of cereal based diets is indeed consistent with other reports in the developing countries (Ekesa et al., 2011; Kiboi et al., 2017) and calls for nutrition interventions that aim to help communities improve their diets.

Results on the determinants of dietary diversity indicated that multiple factors mediate household dietary diversity. Comparing the relative magnitudes of the effects of the variables, food accessibility pathway appears to be the most important in addressing the challenges of low dietary diversity. These results accord broadly with the findings of Oldewage-Theron and Kruger (2011) who found that household food insecurity led to poor food variety, food group diversity scores and subsequently inadequate nutrients. The findings provide further evidence that food insecure households in low-income countries often have diets that are less diverse (Becquey et al., 2010; Hadley et al., 2011; Mailumo et al., 2016; Passarelli et al., 2018). The role of local markets on increasing household dietary diversity was evident in this study. Elsewhere, the impact of food accessibility on dietary quality has been shown to be much stronger for those not engaged in agriculture production (Huang and Tian, 2019; Pritchard et al., 2019). There is increasing evidence from various countries that a substantial share of the food consumed in rural households is purchased from markets (Barrett, 2008; Luckett et al., 2015; Hirvonen et al., 2016). While farm production diversity is positively associated with dietary diversity, market access has been shown to be a more important factor influencing dietary diversity in smallholder farm households (Jones et al., 2014; Koppmair et al., 2017). Market and infrastructural development particularly in villages such as those of the NCA, where no crop production takes places, is more critical if positive nutritional effects are to be realized.

Livelihood diversification which was the second most important factor influencing dietary diversity draws attention on the need for promoting a range of alternative income generating activities other than pastoralism. Beekeeping, in particular, is known for its role in augmenting household income (Kinati et al., 2012; Gebiso, 2015). The higher dietary diversity recorded among those engaged in beekeeping could be the result of improved household income from bee products which was then used to purchase food. Nonetheless, the full potential of the beekeeping subsector has not been realized given that beekeeping in the area predominantly employs traditional system characterized by lack of necessary accessories (e.g., extractors, wax stumpers and bee smokers) and low productivity. This situation underscores the need to increase awareness and leverage interventions on modern beekeeping technology. The present study has also uncovered important linkages between household characteristics and dietary diversity. First, presence of food storage facility in a household was clearly associated with increased chances of more diverse food. It seems, however, that the Maasai perhaps because of a background in transhumance pastoralism have not had a history of using any long-term food storage techniques. Encouraging a culture of storing food would partly address the challenges related to poor food consumption and food security.

Second, an increase in probabilities from Q2 to higher quartiles with livestock units suggests increased income from livestock sales which possibly enabled households to purchase more food varieties. In this regard, however, small stocks are known to be more convenient for sale or consumption at household level (Misiak et al., 2018). Although cattle are considered an index of social status, its meat is rarely eaten (Smith, 2016). Third, the favorable effects of household membership in saving group on dietary diversity could be associated with the positive effects of community banks on household income (Lwezaura and Ngaruko, 2013). Fourth, the observation that dietary diversity increased with household size could be a result of more individuals having different preferences for food types, leading to more diverse diets. Lastly, the negative marginal effects of distance to the nearest road and to the market recorded in Q2 through Q4 imply that longer walking time to these points is associated with reduced access to diverse food. Such households have had reduced chances of being in Q2 or higher quartiles. This 
Curr. Res. J. Soc. Sci., 11(1): 1-12, 2020

finding is plausible given the fact that with an exception of the livestock products, most of the other food groups are typically purchased from the market.

Several limitations need to be stated. First, data were collected in a single round. Thus, the cause effect relationship cannot be established. Second, such data have clear limitations as day-to-day variation in food consumption cannot be captured. While such variation is often relatively low in resource poor households, it cannot be neglected in nutritional assessments. Third, the single-round data do not reflect seasonal variations. There can be marked differences in food availability and food accessibility and, therefore, dietary diversity between the dry season and the wet season. Collecting food consumption data during the wet season would allow for a more complete insight into the Maasai diets. Nevertheless, the present study provides important information on the nutrition-related challenges specific to communities in which livestock are central to their economy, culture and identity.

\section{CONCLUSION}

The findings from this study have highlighted the pattern of consumption of various food groups in pastoral communities of the Ngorongoro Conservation Area. Substantial proportion of households consumed less than the minimum diverse food. Most of the reported diets lacked fruits and vegetables and were characterized with low levels of protein-rich foods. The findings also provide indications that household dietary diversity is dependent on accessibility of food in the local market, livelihood diversification and various demographic and socio-economic factors. Market and infrastructural development coupled with nutrition education would significantly contribute to improved diets and the overall community wellbeing. Promotion of improved nutrition should take into account the physical, demographic and socio-economic factors influencing food consumption and dietary diversity in the study population.

\section{REFERENCES}

Ares, G., L. De Saldamando, A. Giménez and R., Deliza, 2014. Food and wellbeing. Towards a consumer-based approach. Appetite, 74: 61-69.

Århem, K., 1989. Maasai food symbolism: The cultural connotations of milk, meat, and blood in the pastoral Maasai diet. Anthropos, 84: 1-23.

Arsenault, J.E., E.A. Yakes, M.M. Islam, M.B. Hossain, T. Ahmed, C. Hotz, B. Lewis et al., 2013. Very low adequacy of micronutrient intakes by young children and women in rural Bangladesh is primarily explained by low food intake and limited diversity. J. Nutr., 143(2): 197-203.
Barrett, C.B., 2008. Smallholder market participation: Concepts and evidence from eastern and southern Africa. Food Policy, 33(4): 299-317.

Becquey, E., Y. Martin-Prevel, P. Traissac, B. Dembélé, A. Bambara and F. Delpeuch, 2010. The household food insecurity access scale and an index-member dietary diversity score contribute valid and complementary information on household food insecurity in an urban WestAfrican setting. J. Nutr., 140(12): 2233-2240.

Biesalski, H.K., 2013. First international conference on hidden hunger, Hohenheim, Stuttgart, Germany March 6 - 9, 2013. Food Sec., 5: 457-473.

Bilinsky, P. and A. Swindale, 2010. Months of Adequate Household Food Provisioning (MAHFP) for measurement of household food access: Indicator guide (v.4). FHI 360/FANTA, Washington, D.C.

Bostedt, G., A. Hörnell and G. Nyberg, 2016. Agroforestry extension and dietary diversity - an analysis of the importance of fruit and vegetable consumption in West Pokot, Kenya. Food Sec., 8: 271-284.

Brighenti, F., S. Valtuena, N. Pellegrini, D. Ardigo, D. Del Rio, S. Salvatore, P. Piatti, M. Serafini and I. Zavaroni, 2005. Total antioxidant capacity of the diet is inversely and independently related to plasma concentration of high-sensitivity C-reactive protein in adult Italian subjects. Brit. J. Nutr., 93(5): 619-625.

Cano-Ibáñez, N., J.M. Martínez-Galiano, C. AmezcuaPrieto, R. Olmedo-Requena, A. Bueno-Cavanillas and M. Delgado-Rodríguez, 2019. Maternal dietary diversity and risk of small for gestational age newborn: Findings from a case-control study. Clin. Nutr. (in press).

Coates, J., A. Swindale and P. Bilinsky, 2007. Household Food Insecurity Access Scale (HFIAS) for Measurement of Household Food Access: Indicator Guide (v. 3). Food and Nutrition Technical Assistance Project, Academy for Educational Development, Washington, D.C.

Coates, J., B.N. Patenaude, B.L. Rogers, A.C. Roba, Y.K. Woldetensay, A.F. Tilahun and K.L. Spielman, 2018. Intra-household nutrient inequity in rural Ethiopia. Food Policy, 81: 82-94.

Cochran, W.G., 1977. Sampling Techniques. 3rd Edn., John Wiley and Sons, New York.

Coulibaly, J.Y., J. Mango, M. Swamila, A. Tall, H. Kaur and J. Hansen, 2015. What Climate Services do Farmers and Pastoralists Need in Tanzania? Baseline Study for the GFCS Adaptation Program in Africa. Retrieved from: https://ccafs.cgiar.org/publications/what-climateservices-do-farmers-and-pastoralists-needtanzania\#.Xq8gXahKi70. 
Dafursa, K. and S. Gebremedhin, 2019. Dietary diversity among children aged 6-23 months in Aleta Wondo District, Southern Ethiopia. J. Nutr. Metab., 2019: 10.

Dangura, D. and S. Gebremedhin, 2017. Dietary diversity and associated factors among children 623 months of age in Gorche district, Southern Ethiopia: Cross-sectional study. BMC Pediatr., 17(1): 6.

Demilew, Y.M. and A.T. Alem, 2019. Food security is not the only solution to prevent under-nutrition among 6-59 months old children in Western Amhara region, Ethiopia. BMC Pediatr., Vol. 19, Article No. 7.

Ekesa, B.N., G. Blomme and H. Garming, 2011. Dietary diversity and nutritional status of preschool children from Musa-dependent households in Gitega (Burundi) and Butembo (Democratic Republic of Congo). Afr. J. Food Agric. Nutr. Dev., 11(4).

FAO (Food and Agriculture Organization), 1979. Production Year Book. Rome, Italy.

FAO (Food and Agriculture Organization), 2001. Pastoralism in the New Millennium. FAO Animal Production and Health Paper 150, Rome, Italy.

FAO (Food and Agriculture Organization), 2008. Report on Use of the Household Food Insecurity Access Scale and Household Dietary Diversity Score in Two Survey Rounds in Manica and Sofala Provinces, Mozambique, 2006-2007 (v.2). Retrieved from: www.foodsec.org/tr/nut/moz_diet.pdf. (Accessed on: March 5th, 2020).

FAO (Food and Agriculture Organization), 2011. Guidelines for Measuring Household and Individual Dietary Diversity. Rome, Italy.

Farhangi, M.A. and L. Jahangiry, 2018. Dietary diversity score is associated with cardiovascular risk factors and serum adiponectin concentrations in patients with metabolic syndrome. BMC Cardiovasc. Disord., 18(1): 68.

Fenton, C., J. Hatfield and L. McIntyre, 2012. A qualitative pilot study of food insecurity among Maasai women in Tanzania. Pan Afr. Med. J., 12: 81 .

Fetai, B., S. Abduli and S. Qirici, 2015. An ordered probit model of job satisfaction in the former Yugoslav Republic of Macedonia. Proc. Econ. Financ., 33: 350-357.

Field, A., 2013. Discovering Statistics using IBM SPSS Statistics. 4th Edn., SAGE Publications Ltd., London.

Galiè, A., N. Teufel, A.W. Girard, I. Baltenweck, P. Dominguez-Salas, M.J. Price and R. Jones, 2019. Women's empowerment, food security and nutrition of pastoral communities in Tanzania. Glob. Food Sec., 23: 125-134.
Galvin, K.A., T.A. Beeton, R.B. Boone and S.B. Burn Silver, 2015. Nutritional status of Maasai pastoralists under change. Hum. Ecol. Interdiscip. J., 43(3): 411-424.

Gebiso, T., 2015. Adoption of modern bee hive in Arsi Zone of Oromia Region: Determinants and financial benefits. Agric. Sci., 6: 382-396.

Gebremedhin, S., K. Baye, T. Bekele, M. Tharaney, Y. Asrat, Y. Abebe and N. Reta, 2017. Predictors of dietary diversity in children ages 6 to $23 \mathrm{mo}$ in largely food-insecure area of South Wollo, Ethiopia. Nutrition, 33: 163-168.

Gholizadeh, F., J. Moludi, N.L. Yagin, M. Alizadeh, S.M. Nachvak, H. Abdollahzad and M. Mostafazadeh, 2018. The relation of dietary diversity score and food insecurity to metabolic syndrome features and glucose level among prediabetes subjects. Primary Care Diabetes, 12(4): 338-344.

Gomez, P., N. Schneid and F. Delaere, 2015. How often should I eat it? Product correlates and accuracy of estimation of appropriate food consumption frequency. Food Qual. Prefer., 40: 1-7.

Guenther, P.M., J. Reedy, S.M. Krebs-Smith, B.B. Reeve and P.P. Basiotis, 2007. Development and Evaluation of the Healthy Eating Index-2005. Department of Agriculture, Center for Nutrition Policy and Promotion, United States. Retrieved from: http://hdl.handle.net/10919/18682.

Hadley, C., D.A. Linzer, T. Belachew, A.G. Mariam, F. Tessema and D. Lindstrom, 2011. Household capacities, vulnerabilities and food insecurity: Shifts in food insecurity in urban and rural Ethiopia during the 2008 food crisis. Soc. Sci. Med., 73(10): 1534-1542.

Harris-Fry, H., K. Azad, A. Kuddus, S. Shaha, B. Nahar, M. Hossen, L. Younes, A. Costello and E. Fottrell, 2015. Socio-economic determinants of household food security and women's dietary diversity in rural Bangladesh: A cross-sectional study. J. Health Popul. Nutr., 33(1): 2.

Hirvonen, K., A.S. Taffesse and I.W. Hassen, 2016. Seasonality and household diets in Ethiopia. Public Health Nutr., 19(10): 1723-1730.

Hirvonen, K., J. Hoddinott, B. Minten and D. Stifel, 2017. Children's diets, nutrition knowledge, and access to markets. World Dev., 95: 303-315.

Hooshmand, S. and S.A. Udipi, 2013. Dietary diversity and nutritional status of urban primary school children from Iran and India. J. Nutr. Disord. Ther., S12: 5 .

Huang, Y. and X. Tian, 2019. Food accessibility, diversity of agricultural production and dietary pattern in rural China. Food Policy, 84: 92-102.

Ickowitz, A., B. Powell, D. Rowland, A. Jones and T. Sunderland, 2019. Agricultural intensification, dietary diversity, and markets in the global food security narrative. Glob. Food Sec., 20: 9-16. 
Jones, A.D., A. Shrinivas and R. Bezner-Kerr, 2014. Farm production diversity is associated with greater household dietary diversity in Malawi: Findings from nationally representative data. Food Policy, 46: 1-12.

Kang, Y., K.M. Hurley, J. Ruel-Bergeron, A.B. Monclus, R. Oemcke, L.S.F. Wu, M. Mitra et al., 2019. Household food insecurity is associated with low dietary diversity among pregnant and lactating women in rural Malawi. Public Health Nutr., 22(4): 697-705.

Kant, A.K., A. Schatzkin, T.B. Harris, R.G. Ziegler and G. Block, 1993. Dietary diversity and subsequent mortality in the first national health and nutrition examination survey epidemiologic follow-up study. Am. J. Clin. Nutr., 57(3): 434-440.

Kasimba, S.N., B.S. Motswagole, N.M. Covic and N. Claasen, 2018. Household access to traditional and indigenous foods positively associated with food security and dietary diversity in Botswana. Public Health Nutr., 21(6): 1200-1208.

Keding, G.B., J.M. Msuya, B.L. Maass and M.B. Krawinkel, 2012. Relating dietary diversity and food variety scores to vegetable production and socio-economic status of women in rural Tanzania. Food Sec., 4(1): 129-140.

Kiboi, W., J. Kimiywe and P. Chege, 2017. Determinants of dietary diversity among pregnant women in Laikipia County, Kenya: A crosssectional study. BMC Nutr., 3: 12.

Kinati, C., T. Tolemariam, K. Debele and T. Tolosa, 2012. Opportunities and challenges of honey production in Gomma district of Jimma zone, South-west Ethiopia. J. Agric. Ext. Rural Dev., 4(4): 85-91.

Knueppel, D., M. Demment and L. Kaiser, 2010. Validation of the household food insecurity access scale in rural Tanzania. Public Health Nutr., 13(3): 360-367.

Koppmair, S., M. Kassie and M. Qaim, 2017. Farm production, market access and dietary diversity in Malawi. Public Health Nutr., 20(2): 325-335.

Labadarios, D., N.P. Steyn and J. Nel, 2011. How diverse is the diet of adult South Africans? Nutrition J., 10(1): 33.

Lancaster, K.J., 1966. A new approach to consumer theory. J. Polit. Econ.,74: 132-157.

Larson, J.B., P. Castellanos and L. Jensen, 2019. Gender, household food security, and dietary diversity in western Honduras. Glob Food Sec., 20: 170-179.

Li, Y., N.M. Wedick, J. Lai, Y. He, X. Hu, A. Liu, S. Du et al., 2011. Lack of dietary diversity and dyslipidaemia among stunted overweight children: The 2002 China National Nutrition and Health Survey. Public Health Nutr., 14(5): 896-903.
Lo, Y.T., Y.H. Chang, M.S. Lee and M.L. Wahlqvist, 2012. Dietary diversity and food expenditure as indicators of food security in older Taiwanese. Appetite, 58(1): 180-187.

Loos, T.K. and M. Zeller, 2014. Milk sales and dietary diversity among the Maasai. Agric. Econ., 45(S1): 77-90.

Luckett, B.G., F.A. DeClerck, J. Fanzo, A.R. Mundorf and D. Rose, 2015. Application of the nutrition functional diversity indicator to assess food system contributions to dietary diversity and sustainable diets of Malawian households. Public Health Nutr., 18(13): 2479-2487.

Lv, Y., V.B. Kraus, X. Gao, Z. Yin, J. Zhou, C. Mao, J. Duan et al., 2019. Higher dietary diversity scores and protein-rich food consumption were associated with lower risk of all-cause mortality in the oldest old. Clin. Nutr., (in press).

Lwezaura, D. and D. Ngaruko, 2013. Determinants of group participation: Option and impact of farmers' participation in groups in Mbozi District. Afr. J. Econ., 1(2): 47-59.

Lynn, S., 2010. The pastoral to agro-pastoral transition in Tanzania: Human adaptation in an ecosystem context. B.A. Thesis, in Ecology. Fort Collins, Colorado, Colorado State University, pp: 26.

Mahmudiono, T., S. Sumarmi and R.R. Rosenkranz, 2017. Household dietary diversity and child stunting in East Java, Indonesia. Asia Pac. J. Clin. Nutr., 26(2): 317-325.

Mailumo, S.S., S.T. Folorunsho, P.S. Amaza and S. Muhammad, 2016. Analysis of food security and poverty status of rural farming households in Bauchi state, Nigeria. J. Agric. Res. Dev., 15(1): 52-65.

Martin, H., P. Petrucka and J. Buza, 2014. Determination of Vitamins A, C and D status using serum markers and a 24-hour dietary recall among Maasai women of reproductive age. Open Access Library J., 1: e893.

Martin-Prével, Y., P. Allemand, D. Wiesmann, M. Arimond, T. Ballard and M. Deitchler, 2015. Moving Forward on Choosing a Standard Operational Indicator of Women's Dietary Diversity. Food and Agricultural Organization of the United Nations (FAO), Rome, Italy. Retrieved from: http://www.fao.org/3/a-i4942e.pdf.

Mekuria, G., Y. Wubneh and T. Tewabe, 2017. Household dietary diversity and associated factors among residents of Finote selam town, north west Ethiopia: A cross sectional study. BMC Nutr., Vol. 3, Article No. 28.

Misiak, M., M. Butovskaya and P. Sorokowski, 2018. Ecology shapes moral judgments towards foodwasting behavior: Evidence from the Yali of West Papua, the Ngorongoro Maasai, and Poles. Appetite, 125: 124-130. 
Moramarco, S., G. Amerio, L. Chafula Muyaba, D. Bonvecchio, E. Abramo, L. Palombi and E. Buonomo, 2017. Nutritional counseling improves dietary diversity and feeding habits of Zambian malnourished children admitted in Rainbow nutritional programs. Biomed. Prev., Vol. 1.

Mphwanthe, G., D. Weatherspoon, A. Kalimbira and L. Weatherspoon, 2018. Food security, dietary diversity and glycemic control among adults diagnosed with type 2 diabetes in Malawi. J. Nutr. Educ. Behav., 50(7): S13.

Muraoka, R., S. Jin and T.S. Jayne, 2018. Land access, land rental and food security: Evidence from Kenya. Land Use Policy, 70: 611-622.

Muricho, D.N., D.J. Otieno, W. Oluoch-Kosura and M. Jirström, 2019. Building pastoralists' resilience to shocks for sustainable disaster risk mitigation: Lessons from West Pokot County, Kenya. Int. J. Disaster Risk Reduct., 34: 429-435.

Myers, R., 1990. Classical and Modern Regression with Applications. 2nd Edn., Duxbury-Thomson Learning, USA.

Narmaki, E., F. Siassi, F. Koohdani, M. Qorbani, F. Shiraseb, A. Ataie-Jafari and G. Sotoudeh, 2015. Dietary diversity as a proxy measure of blood antioxidant status in women. Nutrition., 31(5): 722-726.

Nti, C.A., 2011. Dietary diversity is associated with nutrient intakes and nutritional status of children in Ghana. Asian J. Med. Sci., 2(2): 105-109.

Oiye, S., J.O. Simel, R. Oniang'o and T. Johns, 2009. The Maasai Food System and Food and Nutrition Security. Retrieved from: http://www.fao.org/tempref/docrep/fao/012/i0370e/ i0370e12.pdf. (Accessed on: March 5th, 2020).

Oldewage-Theron, W. and R. Kruger, 2011. Dietary diversity and adequacy of women caregivers in a peri-urban informal settlement in South Africa. Nutrition, 27(4): 420-427.

Otieno, D.J. and R.A. Nyikal, 2017. Analysis of consumer preferences for quality and safety attributes in artisanal fruit juices in Kenya. J. Food Prod. Mark., 23(7): 817-834.

Passarelli, S., D. Mekonnen, E. Bryan and C. Ringler, 2018. Evaluating the pathways from small-scale irrigation to dietary diversity: Evidence from Ethiopia and Tanzania. Food Secur., 10(4): 981-997.

Perkins, J.M., R. Jayatissa and S.V. Subramanian, 2018. Dietary diversity and anthropometric status and failure among infants and young children in Sri Lanka. Nutrition, 55: 76-83.

Powell, B., S.H. Thilsted, A. Ickowitz, C. Termote, T. Sunderland and A. Herforth, 2015. Improving diets with wild and cultivated biodiversity from across the landscape. Food Secur., 7(3): 535-554.
Pritchard, B., A. Rammohan and M. Vicol, 2019. The importance of non-farm livelihoods for household food security and dietary diversity in rural Myanmar. J. Rural Stud., 67: 89-100.

Rah, J.H., N. Akhter, R.D. Semba, S. De Pee, M.W. Bloem, A.A. Campbell, R. Moench-Pfanner, K. Sun, J. Badham and K. Kraemer, 2010. Low dietary diversity is a predictor of child stunting in rural Bangladesh. Eur. J. Clin. Nutr., 64(12): 1393-1398.

Rimal, A.P., S.M. Fletcher and K.H. McWatters, 2000. Nutrition considerations in food selection. Int. Food Agribus. Man., 3(1): 55-70.

Ritzema, R.S., S. Douxchamps, S. Fraval, A. Bolliger, L. Hok, P. Phengsavanh, C.T.M. Long, J. Hammond and M.T. van Wijk, 2019. Householdlevel drivers of dietary diversity in transitioning agricultural systems: Evidence from the Greater Mekong Subregion. Agr. Syst., 176: 102657.

Rosenberg, A.M., J.A. Maluccio, J. Harris, M. Mwanamwenge, P.H. Nguyen, G. Tembo and R. Rawat, 2018. Nutrition-sensitive agricultural interventions, agricultural diversity, food access and child dietary diversity: Evidence from rural Zambia. Food Policy, 80: 10-23.

Rufino, M.C., P.K. Thornton, S.K. Ng'ang'a, I. Mutie, P.G. Jones, M.T. Van Wijk and M. Herrero, 2013. Transitions in agro-pastoralist systems of East Africa: Impacts on food security and poverty. Agr. Ecosyst. Environ., 179: 215-230.

Sibhatu, K.T., V.V. Krishna and M. Qaim, 2015. Production diversity and dietary diversity in smallholder farm households. P. Natl. Acad. Sci. USA, 112(34): 10657-10662.

Smale, M., M. Moursi and E. Birol, 2015. How does adopting hybrid maize affect dietary diversity on family farms? Micro-evidence from Zambia. Food Policy, 52: 44-53.

Smith, N.M., 2016. "No cow makes this sort of profit": Capital, success, and Maasai gemstone traders in Tanzania. Extr. Ind. Soc., 3(2): 442-449.

Steyn, N.P., J. Nel, D. Labadarios, E.M.W. Maunder and H.S. Kruger, 2014. Which dietary diversity indicator is best to assess micronutrient adequacy in children 1 to $9 \mathrm{y}$ ? Nutrition, 30(1): 55-60.

Tavakoli, S., A.R. Dorosty-Motlagh, A. Hoshiar-Rad, M.R. Eshraghian, G. Sotoudeh, L. Azadbakht, M. Karimi and S. Jalali-Farahani, 2016. Is dietary diversity a proxy measurement of nutrient adequacy in Iranian elderly women? Appetite, 105: 468-476.

Vandevijvere, S., S. De Vriese, I. Huybrechts, M. Moreau and H. Van Oyen, 2010. Overall and within-food group diversity are associated with dietary quality in Belgium. Public Health Nutr., 13(12): 1965-1973. 
Curr. Res. J. Soc. Sci., 11(1): 1-12, 2020

Warren, E., S. Hawkesworth and C. Knai, 2015. Investigating the association between urban agriculture and food security, dietary diversity, and nutritional status: A systematic literature review. Food Policy, 53: 54-66.

Weldehaweria, N.B., K.H. Misgina, M.G. Weldu, Y.S. Gebregiorgis, B.H. Gebrezgi, S.W. Zewdie et al., 2016. Dietary diversity and related factors among lactating women visiting public health facilities in Aksum town, Tigray, Northern Ethiopia. BMC Nutr., Vol. 2, Article No. 38 .

WHO, 2002. World Health Report: Reducing Risks, Promoting Healthy Life. World Health Organisation, Geneva, Switzerland.
Workicho, A., T. Belachew, G.T. Feyissa, B. Wondafrash, C. Lachat, R. Verstraeten and P. Kolsteren, 2016. Household dietary diversity and animal source food consumption in Ethiopia: Evidence from the 2011 welfare monitoring survey. BMC Public Health, Vol. 16, Article No. 1192.

Yanda, P.Z. and C. William, 2010. Livelihoods diversifications and implications on food security and poverty levels in the Maasai plains: The case of Simanjiro district, Northern Tanzania. Afr. J. Environ. Sci. Technol., 4(3): 154-166.

Ziegler, A., 2019. The relevance of attitudinal factors for the acceptance of energy policy measures: A micro-econometric analysis. Ecol. Econ., 157: 129-140. 